\title{
OPEN Toxoplasma gondii infection in domestic and wild felids as public health concerns: a systematic review and meta-analysis
}

\author{
Kareem Hatam-Nahavandi ${ }^{1}$, Rafael Calero-Bernal ${ }^{2}$, Mohammad Taghi Rahimi ${ }^{3}$, \\ Abdol Sattar Pagheh ${ }^{4}$, Mehdi Zarean ${ }^{5}$, Asiyeh Dezhkam ${ }^{1}$ \& Ehsan Ahmadpour ${ }^{6,7,8 \bowtie}$
}

Felidae as definitive hosts for Toxoplasma gondii play a major role in transmission to all warm-blooded animals trough oocysts dissemination. Therefore the current comprehensive study was performed to determine the global status of $T$. gondii infection in domestic and wild felids aiming to provide comprehensive data of interest for further intervention approaching the One Health perspective. Different databases were searched by utilizing particular key words for publications related to $T$. gondii infecting domestic and wild feline host species, worldwide, from 1970 to 2020. The review of 337 reports showed that the seroprevalence of $T$. gondii in domestic cats and wild felids was estimated in $37.5 \%(95 \% \mathrm{Cl} 34.7-40.3)\left(I^{2}=98.3 \%, P<0.001\right)$ and $64 \%(95 \% \mathrm{Cl} 60-67.9)\left(I^{2}=88 \%\right.$, $P<0.0001)$, respectively. The global pooled prevalence of oocysts in the fecal examined specimens from domestic cats was estimated in $2.6 \%(95 \% \mathrm{Cl} 1.9-3.3)\left(I^{2}=96.1 \%, P<0.0001\right)$, and that in fecal samples from wild felids was estimated in $2.4 \%(95 \% \mathrm{Cl} 1.1-4.2)\left(I^{2}=86.4 \%, P<0.0001\right)$. In addition, from 13,252 examined soil samples in 14 reviewed studies, the pooled occurrence of $T$. gondii oocysts was determined in $16.2 \%$ ( $95 \% \mathrm{Cl} 7.66-27.03 \%)$. The observed high rates of anti-T. gondii antibodies seroprevalence levels and oocyst excretion frequency in the felids, along with soil (environmental) contamination with oocysts may constitute a potential threat to animal and public health, and data will result of interest in further prophylaxis programs.

Toxoplasma gondii is an opportunistic and successful coccidian parasite capable of infect virtually all homoeothermic vertebrates, including human beings ${ }^{1,2}$. Domestic cats and other Felidae constitute its specific definitive hosts $^{3}$, and all non-feline animals are regarded as intermediate hosts; however, T. gondii can also undergo asexual reproduction in tissues of Felidae acting as intermediate hosts. First, tachyzoites have active multiplication in tissues, associated to rapid invasion causing harmful effects. Zoites present a special tropism to central nervous system and striated muscle, in which they remain latent confined in a cyst as bradyzoites, leading to a longterm chronic infection until another definitive host ingests the tissue. Then, released bradyzoites penetrate the epithelial cells of small intestine, giving rise to schizonts that will form gamonts and, finally, oocysts ${ }^{4}$. Felids excrete oocysts in their faeces, during a limited time lapse, contaminating soil and water ${ }^{5-8}$. In addition to the domestic cats, and under the view of the available literature, the role of wild Felidae in the epidemiology of $T$. gondii should not be neglected ${ }^{5,9}$. Therefore, felids constitute the key element in the epidemiology of T. gondii since an individual can shed millions of oocyts that can spread the infection to many other susceptible hosts ${ }^{10}$. Several important outbreaks of human toxoplasmosis were epidemiologically linked to oocyst contamination of drinking water ${ }^{11-13}$. By the way, oocysts were not detected in the samples collected from the water reservoir linked

${ }^{1}$ School of Medicine, Iranshahr University of Medical Sciences, Iranshahr, Iran. ${ }^{2}$ SALUVET, Animal Health Department, Faculty of Veterinary Sciences, Complutense University of Madrid, Madrid, Spain. ${ }^{3}$ Center for Health Related Social and Behavioral Sciences Research, Shahroud University of Medical Sciences, Shahroud, Iran. ${ }^{4}$ Infectious Diseases Research Canter, Birjand University of Medical Sciences, Birjand, Iran. ${ }^{5}$ Department of Parasitology and Mycology, Faculty of Medicine, Mashhad University of Medical Sciences, Mashhad, Iran. ${ }^{6}$ Infectious and Tropical Diseases Research Center, Tabriz University of Medical Sciences, Tabriz, Iran. ${ }^{7}$ Immunology Research Center, Tabriz University of Medical Sciences, Tabriz, Iran. ${ }^{8}$ Department of Parasitology and Mycology, Tabriz University of Medical Sciences, Tabriz, Iran. ${ }^{\square}$ email: ehsanahmadpour@ gmail.com 
to a serious Canadian outbreak ${ }^{14}$, but viable oocysts were observed in contents of the intestine of a wild trapped cougar (Felis concolor vancouverensis) and in a fecal pile in close proximity to the reservoir ${ }^{15}$. It is important to highlight that the sporulated oocysts are very resistant and can remain viable and infective for more than 1 year in favourable conditions ${ }^{11,16-18}$. In this regard, a recent paper reviewed the environmental pathways by which $T$. gondii can infect animals and people mostly driven by water, soil or contaminated fresh produce or seafood ${ }^{19}$.

Toxoplasma gondii antibodies have been largely found in cats worldwide, and the seroprevalence degree increases with the age of the cat, suggesting postnatal transmission of $T$. gondii ${ }^{20}$. It is assumed that postnatal sero-conversion in cats is linked to oocysts excretion episodes. The life style of cats influences the occurrence of T. gondii infections since feral cats that hunt for their food will present higher rates than domestic cats with limited access to parasites ${ }^{21}$. Seroprevalence level varied among continents, countries and even cities, linked to many possible environmental factors influencing these variations. As an example, in an urban population of 301 domestic cats in Lyon, France ${ }^{20}$, the anti-T. gondii seroprevalence was only $18.6 \%$, approximately half the prevalence in other surveys in Europe $e^{22,23}$. The control of rodents in the area and feeding of cats by people were considered as protective factors limiting infections. On the other hand, a low income and poor sanitation were not the determining factors for low seropositivity to T. gondii in cats in Durango, Mexico ${ }^{24}$. Since a high density of felines (specially domestic cats) increases the risk of infection and T. gondii prevalence in intermediate hosts, a gradient of prevalence rate of infection has been demonstrated depending on the anthropization degree of the environment ${ }^{25,26}$.

Nearly up to $30 \%$ of the world's human population has had contact with the parasite evidenced by the presence of anti-T. gondii antibodies; while $T$. gondii infections are usually asymptomatic, they can lead to harmful effects, especially in congenital cases and immunocompromissed persons ${ }^{27,28}$. Humans become primarily infected mostly via oral ingestion of viable tissue cysts present in raw or undercooked meat and oocysts contaminating water or foodstuffs ${ }^{6,8,29}$. Nowadays, comprehensive local studies are still necessary to determine the source attribution of human infections; this constitutes an interesting challenge that should be approached under the One Health perspective.

To date, different surveys have been focused on domestic and wild felids in order to determine aspects as seroprevalence rates of anti-T. gondii antibodies, frequency of oocysts excretion and soil presence worldwide ${ }^{30-36}$, but with a certain degree of variance among studies. A systematic review recently assessed the seroprevalence of T. gondii in felids from 1967 to 2017 with a search strategy restricted to articles in English ${ }^{37}$. So that, the present investigation was aimed to determine the global frequency of $T$. gondii infections in domestic cats and wild felids, the occurrence of T. gondii-like oocysts shedding, and the frequency of oocysts in soil; such information will be useful to implement further measures aiming to reduce animal and human infections under a One Health perspective.

\section{Methods}

Search strategy. The review process exactly followed the protocol suggested by the Preferred Reporting Items for Systematic Reviews and Meta-analyses (PRISMA) guidelines (Supplementary data: PRISMA/ STROBE) ${ }^{38}$. We retrieved published studies from the databases of MEDLINE (via PubMed) (https://www.ncbi. nlm.nih.gov/pubmed/), Scopus (https://www.scopus.com/), Web of Science (https://www.webofknowledge. $\mathrm{com} /$ ) and CAB Abstracts (https://www.cabi.org/AHPC) with no restriction on language from Jan 1, 1970, to Dec 31, 2019. Search terms included a combination of Medical Subject Heading terms (MeSH) and free-text words in titles, abstracts and full texts.

The systematic search for PubMed accomplished using several Medical Subject Heading terms (Table S1). In addition, Scopus, Web of Science and CAB Abstracts were searched using the same strategy (Supplementary DATA). The Google Scholar search engine was used for checking the search strategy. The reference lists of all included articles and relevant reviews were hand searched for potentially eligible literature. In addition, authors and experts in the field were consulted to aid in the identification of relevant conference abstracts related to Toxoplasma and toxoplasmosis. Sometimes, we have had to contact the authors for raw data collection ${ }^{39}$, especially in old literature.

Selection of studies. Initial screening by manuscript titles and abstracts was performed independently by two researchers (KHN and EA), that also assessed the full texts of all potentially relevant studies and applied inclusion criteria. Discrepancies when detected, were resolved after constructive discussion (AD, MZ and MTR).

The studies providing data on the seroprevalence of $T$. gondii in domestic or wild felids, frequency of oocyst excretion in felids, and those reporting soil contaminations with oocysts were included. On the other hand, studies meeting the epidemiology of $T$. gondii in non-feline hosts, studies where cat faecal samples were collected from the ground, and data from each animal was not independently retrievable, experimental studies, articles that only presented the final result and did not provide the raw data, or those without definite sample size, abstracts presented in congresses without full text, and case-control studies and clinical trials that could not report a correct estimate of prevalence were excluded. Any duplicated research was also excluded.

Quality assessment. The standard Strengthening the Reporting of Observational Studies in Epidemiology (STROBE) checklist was used ${ }^{40}$. In present study, articles were evaluated as low quality: less than 16.5, moderate quality: 16.6-25.5, and high quality: 25.6-34; the articles included in the meta-analysis presented acceptable quality.

Data extraction. After comprehensive examination of selected articles, the following data were extracted: the first author's last name, publication year, country, feline scientific names, keeping status of felids, sample size, 
source of soil samples, beginning and end date of study implementation, the number of the positive and negative cases, cut-off, age groups, as well as information about diagnostic tools. Data were extracted separately if two different populations had been studied. All extracted data from each study were entered into an Excel spreadsheet.

Meta-analysis. The collected data were entered into the StatsDirect statistical software package (version 2.7.2) (Stata Corporation, College Station, TX, USA) (http://www.statsdirect.com/). Statistical heterogeneity of the different years among studies was assessed using the Cochrane's Q test and inconsistency $I^{2}$ test. To determine whether there is a significant heterogeneity, a random effect model was used to estimate the pooled prevalence's of cat infection ${ }^{41}$. In addition, potential publication bias was explored using Funnel plot and Egger's test.

\section{Results}

The initial database search retrieved 14,870 publications. First screening enabled us to exclude 14,441 studies not meeting the inclusion criteria. Altogether, 429 studies were retained for further investigation. In a secondary assessment, another 34 documents were excluded because of one of the following reasons: review articles, follow up studies or case series reports, and papers with insufficient data, or data from each animal were not independently retrievable. Eventually, 395 studies which met our eligibility criteria and evaluated soil contamination with T. gondii oocysts $(n=14)$, and T. gondii infection in domestic cats (serology, $n=268$; oocyst in feces, $n=112$ ) and wild felids (serology, $n=69$; oocyst in feces, $n=15$ ) during five decades were retained for analysis (Fig. 1). Potential publication bias in the conducted studies regarding the prevalence of $T$. gondii infection in domestic cats and wild felids, Toxoplasma-like oocysts shedding, and frequency of oocysts in soil are shown using Funnel plot and Egger's test (Fig. 2).

Prevalence of anti-T. gondii antibodies in blood/serum samples. The global pooled seroprevalence of T. gondii in domestic cats was estimated in 37.5\% (95\% CI 34.7-40.3) $\left(I^{2}=98.3 \%, P<0.001\right)$ (Table 1). The highest rate was observed in Australia (66.6\%, 95\% CI 62.8-70.3) $\left(I^{2}=97.2 \%, P<0.0001\right)$, followed by Africa (55.7\%, 95\% CI 35.6-74.8) $\left(I^{2}=98.9 \%, P<0.0001\right)$, Europe (45.3\%, 95\% CI 41.1-49.6) $\left(I^{2}=96.7 \%, P<0.0001\right)$, Central and South America $(40.3 \%, 95 \%$ CI $34-49.6)\left(I^{2}=97.7 \%, P<0.0001\right)$ and North America $(31.6 \%, 95 \%$ CI 27-36.4) $\left(I^{2}=96.8 \%, P<0.0001\right)$. The lowest prevalence was observed in Asia $(28.3 \%, 95 \%$ CI $24.1-32.6)$ $\left(I^{2}=98.1 \%, P<0.0001\right)$ (Table 1$)$. In the other hand, the worldwide pooled seroprevalence of $T$. gondii in wild felids (including lion, jaguarundi, jaguar, ocelot, cougar, leopard, tiger, geoffroy's cat, oncilla, margay, caracal, snow leopard, Eurasian lynx, bobcat, cheetah, Prionailurus cats, Iberian lynx, pampas cat, serval, pallas's cat, jungle cat, European wildcat, sand cat, Asian golden cat, Canadian lynx, clouded leopard, masked palm civet, and common genet) was estimated 64\% (95\% CI 60-67.9) $\left(I^{2}=88 \%, P<0.0001\right)$ (Table 2). The highest and the lowest seroprevalence rates were related to Panthera leo (87.6\%, 95\% CI 79-94.3) and Leopardus colocolo (19.6\%, 95\% CI 6.1-38.3), respectively (Table 2). Heterogeneity was, however, very low $I^{2}=79.9 \%$. Retrieved information of the eligible studies based on the of anti-Toxoplasma antibodies prevalence in domestic cats and wild felids are summarized in Tables S2 and S3. In total, 80,087 blood samples from domestic cats $(n=73,980)$ and wild felids $(n=6,107)$ from 337 eligible studies were examined for the presence of anti-T. gondii antibodies and/or T. gondii DNA, of which 26,903 subjects were diagnosed as positive (domestic cats $n=23,593$; wild felids $n=3,310$ ) (Tables S2, S3). Different diagnostic methods to evaluate anti-T. gondii antibodies in the cats have been identified in the studies: MAT (132 studies), IFAT (99 studies), and ELISA (92 studies) (Tables S2, S3). Amongst the reviewed studies, just one investigation applied PCR method for detection of $T$. gondii DNA in stray cats using blood samples ${ }^{42}$ (Table S2).

Occurrence of $\boldsymbol{T}$. gondii oocysts in fecal samples. A total number of 137 eligible studies which examined 66,601 fecal samples from domestic cats $(n=63,458)$ and wild felids $(n=3,143), 1,330$ were positive (domestic cats $n=1,254$; wild felids $n=76$ ) for T. gondii oocysts, T. gondii-like oocysts, and/or T. gondii DNA (Table S4, S5). The global pooled prevalence of oocysts in the fecal examined specimens from domestic cats was estimated in $2.6 \%(95 \%$ CI $1.9-3.3)\left(I^{2}=96.1 \%, P<0.0001\right)$ (Table 3). The highest and the lowest prevalence rates were detected in Africa $(9.8 \%, 95 \%$ CI $2.4-21.5)\left(I^{2}=94.1 \%, P<0.0001\right)$, and North America $(0.9 \%, 95 \%$ CI $0.5-1.3)$, respectively. Heterogeneity was, however, very low $I^{2}=50 \%$ (Tables 1,3 ). The most used methodology for detection of oocysts was microscopy (99 studies) which was followed by molecular (16 studies) and mouse bioassay (10 studies) methods (Table S4). Some studies combined two techniques for detection of oocysts in feline feces. The highest prevalence was related to the molecular detection method $(6.5 \%, 95 \%$ CI $3.7-10)\left(I^{2}=92.1 \%\right.$, $P<0.0001)$, followed by bioassay $(2.8 \%, 95 \%$ CI $0.6-6.4)\left(I^{2}=95.1 \%, P<0.0001\right)$, and microscopy $(2.1 \%, 95 \% \mathrm{CI}$ 1.4-2.8) $\left(I^{2}=96.3 \%, P<0.0001\right)$ (Table 3$)$.

The worldwide pooled prevalence of $T$. gondii oocysts, T. gondii-like oocysts and T. gondii DNA in fecal specimens from wild felids was estimated in $2.4 \%(95 \%$ CI $1.1-4.2)\left(I^{2}=86.4 \%, P<0.0001\right)$ (Table 3$)$. The highest and the lowest prevalence of oocysts in fecal specimens was related to Leopardus pardalis (15.89\%, 95\% CI 0.2-58.6) and Panthera onca (3.5\%, 95\% CI 1.3-13.7), respectively (Table S5). The prevalence of Toxoplasma-like oocysts detected in domestic and wild feline stool samples in different countries are shown in Fig. 3. As well India (49\%) and Colombia (33\%) had the highest prevalence.

Occurrence of T. gondii oocysts in soil samples. Up to 14 studies reported the examination of 13,252 soil specimens resulting in 3,421 (25.8\%) samples positive for T. gondii oocysts (or T. gondii-DNA) using mouse bioassay and different PCR procedures. Table S6 shows the conducted studies to detect T. gondii oocysts in soil samples; the pooled prevalence of T. gondii oocysts in those samples was estimated $16.2 \%$ (95\% CI 7.66-27.03\%) $\left(\mathrm{Q}=1628.10, I^{2}=99.2 \%, P<0.0001\right)$ (Egger's bias $\left.=5.44, P=0.3733\right)($ Fig. 4$)$. 


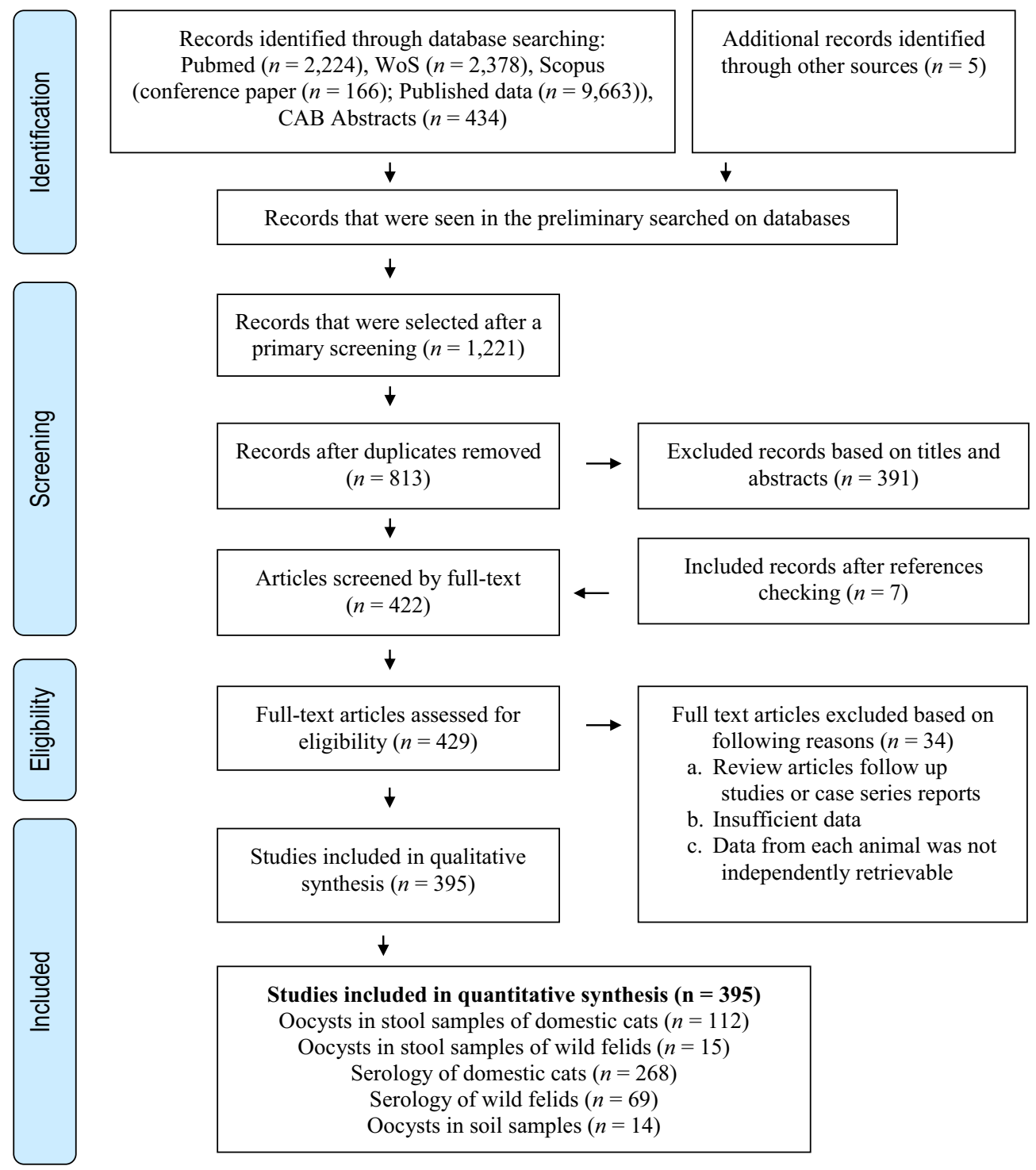

Figure 1. Flowchart of the study design process.

\section{Discussion}

Felids as final host play an irreplaceable role for T. gondii life cycle that exclusively yield and excrete oocysts in their faeces, contaminating soil, water and food ${ }^{6-8,10}$. According to our findings, $37.5 \%$ of domestic cats showed exposure to $T$. gondii and $2.6 \%$ were actively shedding T. gondii or T. gondii-like oocysts. Similarly, the worldwide seroprevalence of Toxoplasma in domestic cats had been previously estimated at levels of $30-40 \%{ }^{1,43}$.

Based on the results, the highest value of seroprevalence in domestic cats was observed in Australia, followed by Africa, Europe, Central/South America, North America and Asia; although the number of studies for Australia $(n=6)$ and Africa $(n=15)$ were relatively low, whereas only one study in USA included 12,628 animals. The lowest prevalence was observed in Asia (28.3\%), nevertheless, most studies have been conducted in Asian countries (91 studies). The number of surveys was higher in USA (North America; 34 studies), followed by Brazil (South America; 30 studies). Our investigation identified a number of countries without any data on $T$. gondii infection in cats, emphasizing the need for further studies in this field. According to our findings, $64 \%$ of nondomestic cats showed evidence of exposure to T. gondii and $2.4 \%$ were actively shedding T. gondii oocysts. Accordingly, the highest sero-prevalence of T. gondii in different wild felids were in the following order: lion (Panthera leo), European wildcat (Felis silvestris), jaguar (Panthera onca), Pallas's cat (Otocolobus manul), sand cat (Felis margarita), cheetah (Acinonyx jubatus), caracal (Caracal caracal), leopard (Panthera pardus), Iberian lynx (Lynx pardinus), ocelot (Leopardus pardalis), tiger (Panthera tigris), serval (Leptailurus serval), Geoffroy's cat (Leopardus geoffroyi), bobcat (Lynx rufus), oncilla (Leopardus tigrinus), cougar (Puma concolor), margay (Leopardus wiedii), snow leopard (Panthera uncial), jaguarundi (Herpailurus yagouaroundi), Asian golden cat (Catopuma temminckii), Eurasian lynx (Lynx lynx), jungle cat (Felis chaus), Prionailurus cat (Prionailurus viverrinus), Canadian lynx (Lynx canadiensis), clouded leopard (Neofelis nebulosa), and Pampas cat (Leopardus 


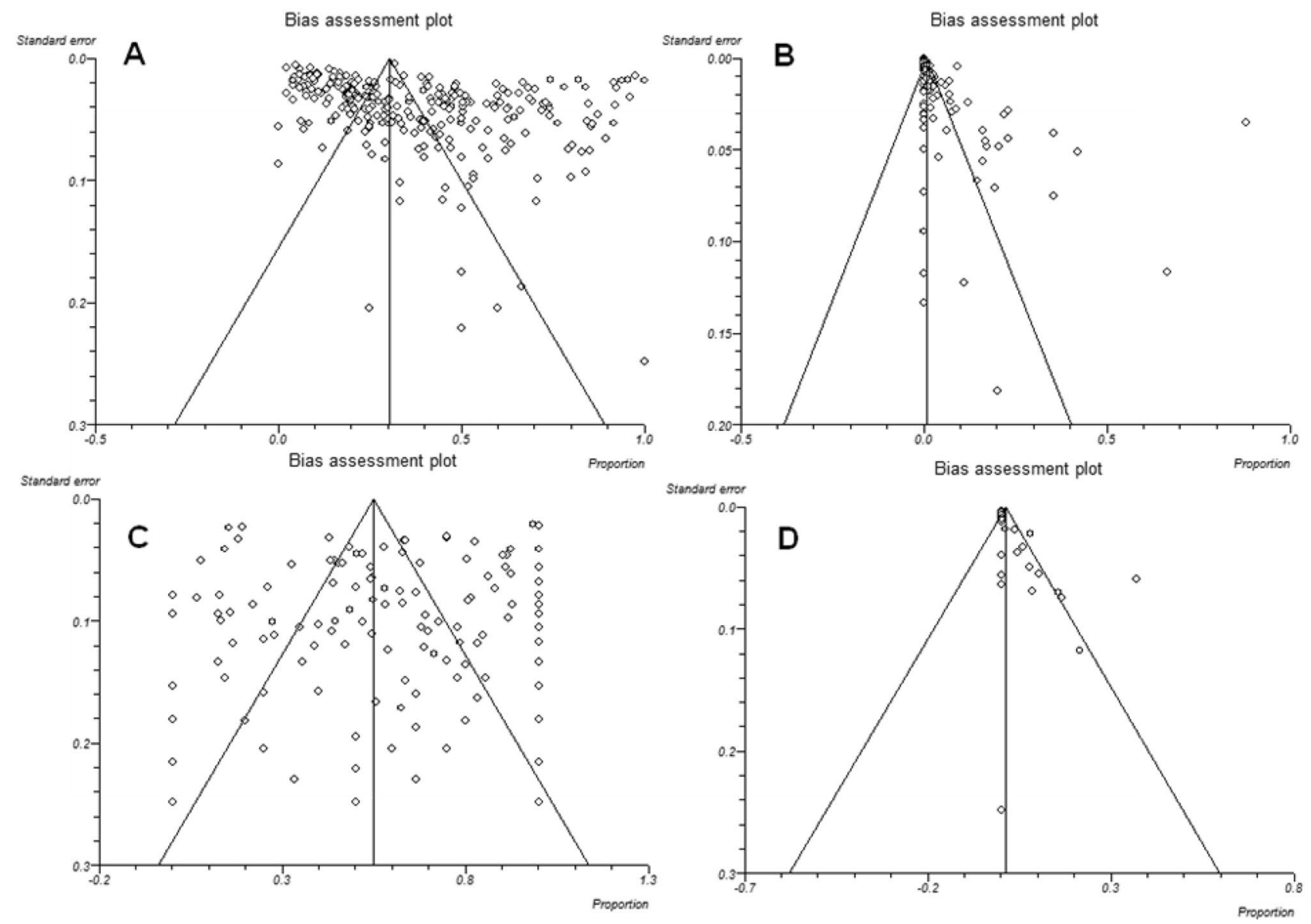

Figure 2. Funnel plot of standard error by logit event rate to assess publication or other types of bias across prevalence studies. (A) Studies based on the seroprevalence of anti-Toxoplasma gondii antibodies in domestic cats, (B) studies based on detection of T. gondii-like oocyst and T. gondii oocyst DNA in domestic cat feces, (C) studies based on the seroprevalence of anti-Toxoplasma gondii antibodies in wild felids, (D) studies based on detection of T. gondii-like oocyst and T. gondii oocyst DNA in wild felids feces.

\begin{tabular}{|c|c|c|c|c|c|c|c|c|}
\hline \multirow[b]{2}{*}{ Continent } & \multirow[b]{2}{*}{ No. of studies } & \multirow[b]{2}{*}{ Detection method } & \multirow[b]{2}{*}{ Prevalence \% $(95 \% \mathrm{CI})$} & \multicolumn{3}{|c|}{ Heterogeneity } & \multicolumn{2}{|c|}{ Egger's test } \\
\hline & & & & $\mathrm{I}_{2}$ & Q & P value & $\mathbf{T}$ & $P$ value \\
\hline \multirow{2}{*}{ Africa } & 6 & Stool exam & $9.8(2.4-21.5)$ & 94.1 & 84.2 & $<0.0001$ & 5.1 & 0.0434 \\
\hline & 16 & Serology & $55.7(35.6-74.8)$ & 98.9 & 1408.4 & $<0.0001$ & -3.8 & 0.6571 \\
\hline \multirow{2}{*}{ Asia } & 32 & Stool exam & $4(1.9-6.9)$ & 96.9 & 1001.4 & $<0.0001$ & 3.2 & 0.0195 \\
\hline & 90 & \begin{tabular}{|l|} 
Serology \\
\end{tabular} & $28.3(24.1-32.6)$ & 98.1 & 4730.5 & $<0.0001$ & 7.7 & $<0.0001$ \\
\hline \multirow{2}{*}{ Australia } & 4 & Stool exam & $1.7(0.2-4.5)$ & 79.1 & 14.3 & 0.0025 & 1.3 & 0.3488 \\
\hline & 6 & \begin{tabular}{|l|} 
Serology \\
\end{tabular} & $66.6(62.8-70.3)$ & 97.2 & 176.1 & $<0.0001$ & -9.66 & 0.1256 \\
\hline \multirow{2}{*}{ Europe } & 55 & Stool exam & $1.21(0.8-1.6)$ & 89.6 & 517.1 & $<0.0001$ & 1.18 & $<0.0001$ \\
\hline & 61 & Serology & $45.3(41.1-49.6)$ & 96.7 & 1840.1 & $<0.0001$ & 2.94 & 0.1269 \\
\hline \multirow{2}{*}{ North America } & 16 & Stool exam & $0.9(0.5-1.3)$ & 50.0 & 30.3 & 0.0108 & 0.94 & 0.0583 \\
\hline & 37 & Serology & $31.6(27-36.4)$ & 96.8 & 1126.2 & $<0.0001$ & 0.49 & 0.7212 \\
\hline \multirow{2}{*}{ Central/South America } & 12 & Stool exam & $6.2(1.8-1.3)$ & 97.1 & 374.2 & $<0.0001$ & 3.4 & 0.0226 \\
\hline & 61 & Serology & $40.3(34.0-46.8)$ & 97.7 & 2642.3 & $<0.0001$ & 4.5 & 0.0467 \\
\hline
\end{tabular}

Table 1. Pooled prevalence of Toxoplasma infection in domestic cats and subgroup analyses.

colocolo). Although in general it should be considered that the number of studied nondomestic cats were lower compared to domestic cats, and keeping status of wilds cats, in captive $(n=2,492)$ or free ranging $(n=2,949)$, is probably associated with how they are fed and how they become infected. Albeit such findings also highlights the importance of serological and isolation studies on $T$. gondii infecting their prey (ungulates, birds, etc.) using validated methodologies for bias reducing. 


\begin{tabular}{|c|c|c|c|c|c|c|c|c|}
\hline \multirow[b]{2}{*}{ Host species } & \multirow[b]{2}{*}{ No. of studies } & \multirow[b]{2}{*}{ Detection method } & \multirow[b]{2}{*}{ Prevalence $(95 \% \mathrm{CI})$} & \multicolumn{3}{|c|}{ Heterogeneity } & \multicolumn{2}{|c|}{ Egger's test } \\
\hline & & & & $\mathrm{I}_{2}$ & Q & $P$ value & T & $P$ value \\
\hline $\begin{array}{l}\text { Asian golden cat (Catopuma } \\
\text { temminckii) }\end{array}$ & 3 & Serology & $47.1(8.9-87.4)$ & 72.7 & 7.3 & 0.0256 & - & - \\
\hline \multirow{2}{*}{ Bobcat (Lynx rufus) } & 18 & Serology & $60.5(47.1-73.1)$ & 91.0 & 189.8 & $<0.0001$ & 1.5 & 0.3255 \\
\hline & 5 & Stool exam & $4.1(0.2-12.4)$ & 82.5 & 22.8 & 0.0001 & 1.0 & 0.1297 \\
\hline $\begin{array}{l}\text { Canadian Lynx (Lynx } \\
\text { canadiensis) }\end{array}$ & 3 & Serology & $36.4(10.8-67.2)$ & 91.7 & 24.1 & $<0.0001$ & - & - \\
\hline Caracal (Caracal caracal) & 7 & Serology & $69.9(49.6-86.8)$ & 0.0 & 5.1 & 0.5270 & -0.3 & 0.9283 \\
\hline Cheetah (Acinonyx jubatus) & 8 & Serology & $70.4(48.1-88.5)$ & 81.0 & 36.7 & $<0.0001$ & -0.6 & 0.7904 \\
\hline $\begin{array}{l}\text { Clouded leopard (Neofelis } \\
\text { nebulosa) }\end{array}$ & 4 & Serology & $36.3(9.0-69.7)$ & 65.8 & 8.7 & 0.0325 & 4.2 & 0.2131 \\
\hline \multirow{2}{*}{ Cougar (Puma concolor) } & 24 & Serology & $56.1(43.7-68.2)$ & 93.8 & 371.7 & $<0.0001$ & 2.6 & 0.1155 \\
\hline & 6 & Stool exam & $4.7(0.5-12.7)$ & 61.5 & 12.9 & 0.0236 & 0.8 & 0.0955 \\
\hline Eurasian lynx (Lynx lynx) & 6 & Serology & $42.1(14.9-72.2)$ & 97.4 & 192.1 & $<0.0001$ & 1.7 & 0.7428 \\
\hline $\begin{array}{l}\text { European wildcat (Felis } \\
\text { silvestris) }\end{array}$ & 7 & Serology & $76.8(62.6-88.5)$ & 46.0 & 11.1 & 0.0848 & 0.5 & 0.6714 \\
\hline $\begin{array}{l}\text { Geoffroy's cat (Leopardus } \\
\text { geoffroyi) }\end{array}$ & 5 & Serology & $60.7(39.9-79.6)$ & 60.8 & 10.1 & 0.0373 & 1.7 & 0.6131 \\
\hline $\begin{array}{l}\text { Iberian Lynx (Lynx pardi- } \\
\text { nus) }\end{array}$ & 4 & Serology & $66.2(50.1-80.5)$ & 81.9 & 16.5 & 0.0009 & 2.9 & 0.6198 \\
\hline \multirow{2}{*}{ Jaguar (Panthera onca) } & 9 & Serology & $74.4(63.5-84)$ & 61.6 & 20.8 & 0.0076 & 1.7 & 0.1306 \\
\hline & 3 & Stool exam & $3.5(1.3-13.7)$ & 66.9 & 6.0 & 0.0487 & - & - \\
\hline $\begin{array}{l}\text { Jaguarundi (Herpailurus } \\
\text { yagouaroundi) }\end{array}$ & 10 & Serology & $47.7(41.6-53.9)$ & 0.0 & 8.5 & 0.4774 & 1.9 & 0.0053 \\
\hline Jungle cat (Felis chaus) & 2 & Serology & $44.5(7.5-97.1)$ & - & 7.9 & 0.0047 & - & - \\
\hline \multirow{2}{*}{ Leopard (Panthera pardus) } & 17 & Serology & $68.0(46.5-86.1)$ & 72.5 & 58.1 & $<0.0001$ & 5.1 & 0.0010 \\
\hline & 3 & Stool exam & $3.8(0.1-17.6)$ & 84.9 & 13.2 & 0.0013 & - & - \\
\hline \multirow{2}{*}{ Lion (Panthera leo) } & 20 & Serology & $87.6(79-94.3)$ & 79.9 & 94.6 & $<0.0001$ & -1.6 & 0.0175 \\
\hline & 3 & Stool exam & $4.9(0.3-23.8)$ & 85.6 & 13.8 & 1.0010 & - & - \\
\hline Margay (Leopardus wiedii) & 5 & Serology & $56.0(46.4-65.4)$ & 29.0 & 5.6 & 0.2282 & 2.3 & 0.2958 \\
\hline \multirow{2}{*}{ Ocelot (Leopardus pardalis) } & 11 & Serology & $66.2(58.1-73.8)$ & 45.6 & 18.3 & 0.0489 & 1.6 & 0.0921 \\
\hline & 3 & Stool exam & $15.9(0.2-58.6)$ & 85.5 & 13.7 & 0.0010 & - & - \\
\hline Oncilla (Leopardus tigrinus) & 9 & Serology & $59.0(49.7-68)$ & 47.9 & 15.3 & 0.0527 & 1.4 & 0.2027 \\
\hline $\begin{array}{l}\text { Pallas's cat (Otocolobus } \\
\text { manul) }\end{array}$ & 10 & Serology & $70.6(43.9-91.3)$ & 89.3 & 84.1 & $<0.0001$ & -2.4 & 0.4067 \\
\hline $\begin{array}{l}\text { Pampas cat (Leopardus } \\
\text { colocolo) }\end{array}$ & 3 & Serology & $19.6(6.1-38.3)$ & 0.0 & 0.7 & 0.6878 & - & - \\
\hline \multirow{2}{*}{$\begin{array}{l}\text { Prionailurus cats (Prionailu- } \\
\text { rus viverrinus) }\end{array}$} & 10 & Serology & $39.6(24.3-56.1)$ & 60.0 & 22.4 & 0.0075 & 2.5 & 0.0606 \\
\hline & 5 & Stool exam & $4.0(1.8-7.1)$ & 0.0 & 1.4 & 0.8433 & -0.2 & 0.4709 \\
\hline Sand cat (Felis margarita) & 4 & Serology & $70.5(49.9-87.5)$ & 66.8 & 9.0 & 0.0287 & 3.0 & 0.2817 \\
\hline Serval (Leptailurus serval) & 4 & Serology & $64.3(35$ to 88.6$)$ & 8.8 & 3.2 & 0.3493 & -4.1 & 0.7970 \\
\hline $\begin{array}{l}\text { Snow leopard (Panthera } \\
\text { uncial) }\end{array}$ & 2 & Serology & $52.6(10.7-92.2)$ & - & 1.9 & 0.1607 & - & - \\
\hline \multirow{2}{*}{ Tiger (Panthera tigris) } & 16 & Serology & $66.2(51.4-79.5)$ & 61.9 & 39.3 & 0.0006 & 1.3 & 0.3862 \\
\hline & 4 & Stool exam & $7.4(0-27.4)$ & 80.2 & 15.1 & 0.0017 & 1.8 & 0.2827 \\
\hline
\end{tabular}

Table 2. Pooled prevalence of Toxoplasma infection in wild felids and subgroup analyses.

The considerable gap between the prevalence of oocysts in feces and positive serum antibodies can be explained by the fact that infected felids can shed T. gondii oocysts for a short period (10-15 days), shortly after primoinfection, and then they become seropositive indefinitely. As, one important point, the activation of humoral immunity and antibodies production prevent from re-shedding of oocysts; new excretion episodes can occur when severe immunosuppression appears ${ }^{29,44}$. The short period of oocyst shedding and the low prevalence rate of felids which actively excrete oocysts, have led some authors to discuss that direct contact with felids should not be considered as a risk factor for human infection ${ }^{7,29,45}$. A systematic review in Iran showed that humans with history of close contact with cats presented a higher T. gondii seroprevalence rate compared to those without contact ${ }^{46}$. In the study conducted by Jones and colleagues ${ }^{29}$ in the USA, exposure to kittens was statistically linked to T. gondii infection. In the study conducted in different European centers ${ }^{45}$, infections in pregnant women were attributed to the consumption of undercooked or cured meat products and soil contact in the $30-63 \%$ and $6-17 \%$ of cases respectively, but contact with cats was not identified as a risk factor. Similarly, another study showed that contact with cats is not related to infections, while the ingestion of raw or undercooked meat highly increased the risk of infection ${ }^{47}$. 


\begin{tabular}{|c|c|c|c|c|c|}
\hline \multirow[b]{2}{*}{ Group } & \multirow[b]{2}{*}{ Number of studies } & \multirow[b]{2}{*}{ Pooled prevalence $(95 \% \mathrm{CI})$} & \multicolumn{3}{|c|}{ Heterogeneity } \\
\hline & & & $P$ value & $\mathbf{I}^{2}$ & Cochran Q \\
\hline \multicolumn{6}{|c|}{ Domestic Cat } \\
\hline Serology & 271 & $37.5(34.7-40.3)$ & $<0.0010$ & 98.3 & $15,984.3$ \\
\hline Stool exam & 125 & $2.6(1.9-3.3)$ & $<0.0001$ & 96.1 & 3164.3 \\
\hline Microscopy & 99 & $2.1(1.4-2.8)$ & $<0.0001$ & 96.3 & 2664.6 \\
\hline Bioassay & 10 & $2.8(0.6-6.4)$ & $<0.0001$ & 95.1 & 182.7 \\
\hline Molecular & 16 & $6.5(3.7-10)$ & $<0.0001$ & 92.1 & 189.3 \\
\hline \multicolumn{6}{|l|}{\begin{tabular}{|l|} 
Wild Feline \\
\end{tabular}} \\
\hline Serology & 223 & $64.0(60-67.9)$ & $<0.0001$ & 88 & 1854.9 \\
\hline Stool exam & 12 & $2.4(1.1-4.2)$ & $<0.0001$ & 86.4 & 227.5 \\
\hline
\end{tabular}

Table 3. The global pooled prevalence of Toxoplasma infection in feline hosts/felids.

\section{Proportion meta-analysis plot [random effects]}

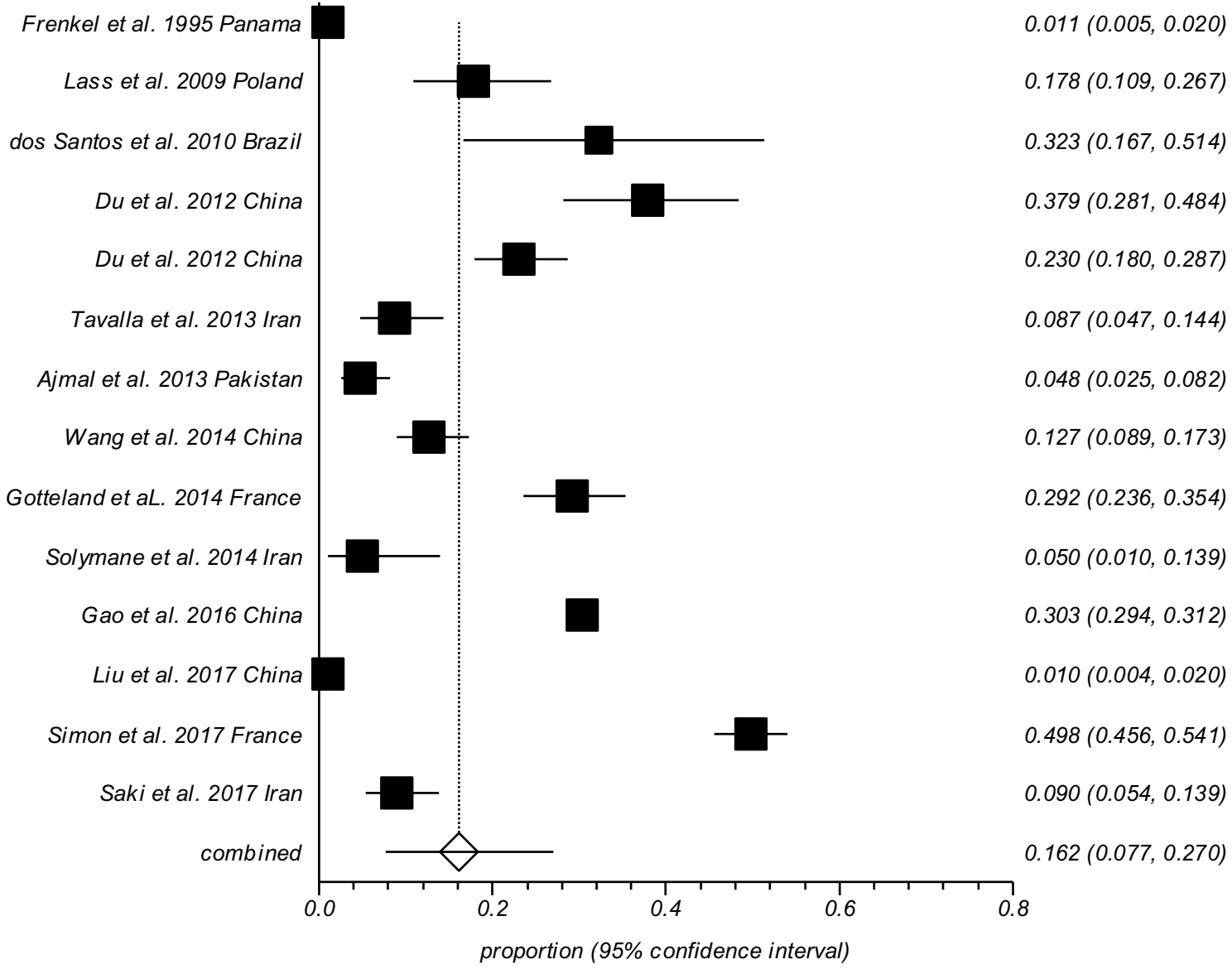

Figure 3. Forest plot diagram of the present systematic review and meta-analysis based on studies focused on detection of soil contamination by Toxoplasma-like oocysts.

Based on the results, $16.2 \%$ of soil samples contained T. gondii oocysts (or T. gondii-DNA), those when sporulated can survive for several months under tough conditions and are resistant to common disinfectants ${ }^{48}$. Contaminated soil has been demonstrated as an important source for infection for humans and animals ${ }^{13,19}$. It has been shown that gardening and occupations in contact with soil increases the risk of T. gondii infection ${ }^{49}$, as previously seen $^{50}$. In a follow-up study of the toxoplasmosis outbreak during 1977 in Georgia ${ }^{51}$, after 25 years, among 37 individual (exposure to an indoor horse arena), 14 equestrian were tested, that three (21\%) were found to have toxoplasmic retinochoroiditis lesions. Based on the observations is possible that cat feces containing the 


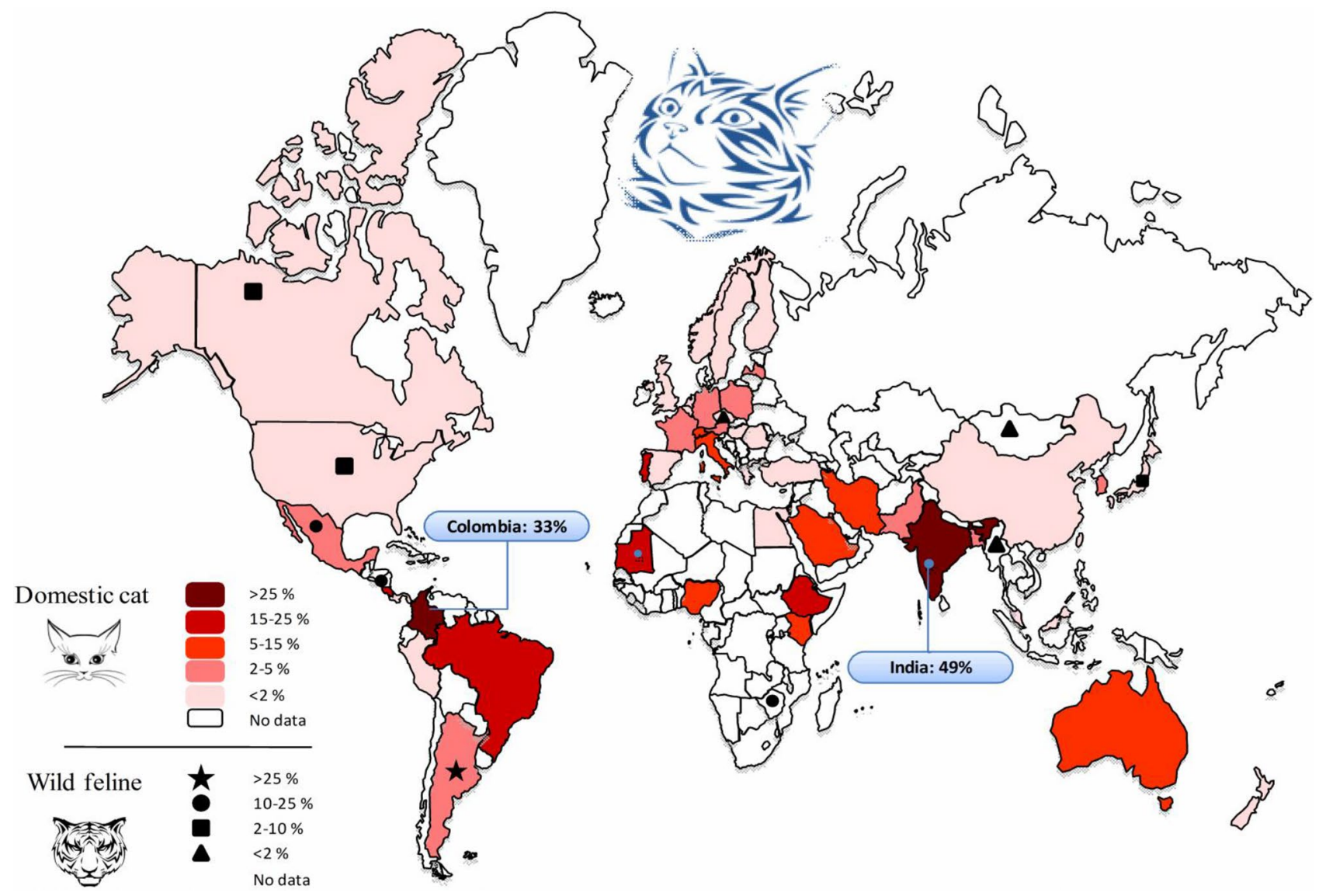

Figure 4. Pooled prevalence of Toxoplasma-like oocysts detected in domestic and wild feline stool samples in different countries (Map created by PowerPoint Microsoft office, source of image: https://commons.wikimedia. org/wiki/File:BlankMap-World.svg).

organism were most likely stirred up when horses ran on the dirt floor, and were inhaled or ingested by riders and observers. Based upon number of studies conducted in different European centers, contact with soil or vegetables or fruit presumably contaminated with soil were highly associated to T. gondii infection in pregnant women $^{45,52-54}$. Investigation on sentinels (i.e., molluscs) for environmental contamination ${ }^{55}$ and also the infection source attribution by using specific tests ${ }^{56}$ will be of great interest for integration with data compilation in definitive and intermediate susceptible hosts.

In the present investigation, the prevalence of soil contamination was highly variable in the selected studies, which might be influenced by the soil characteristics and the number of infected animals in the area ${ }^{57}$. The included studies also reported highly heterogeneous results regarding the prevalence of cat infections, which could be due to the different risk factors, to note: sex, age, climates, study periods, cat breeds, living conditions and diagnostic methods as well as other unrecognized confounding factors. Based on our results, T. gondii seroprevalence in cats (Felis domesticus) in different countries oscillated from less than $10 \%$ in Thailand, Taiwan and Angola to more than $70 \%$ in Qatar, and Ethiopia. This can partly be explained by the different environmental conditions among the countries ${ }^{58}$. It has been shown that cat infections present higher occurrence in warm, moist and low altitude regions, maybe linked to oocysts sporulation and survival of $T$. gondii oocysts in such latitudes ${ }^{34}$. Similarly, T. gondii seroprevalence in pigs was associated with lower geographical latitude and higher mean annual temperature ${ }^{59}$, fact that may suggest high environmental contamination with T. gondii sporulated oocysts. It seems to be clear that oocysts shedding by cats constitute the essential element for sustainment of the parasite in the environment, this was demonstrated when extremely low seroprevalence of $T$. gondii $(0.9 \%)$ was detected in feral pigs from a remote island lacking cats in the USA ${ }^{60}$. Furthermore, the time period of study might influence the results, as the infection rate is higher in autumn, winter ${ }^{22}$, and rainy years ${ }^{20}$. One may consider breed as a variable factor for cat T. gondii infection. It has been shown that Toxoplasma seroprevalence is highly variable in different cat breeds from $18.8 \%$ in Burmese cats to $60 \%$ in Persian cats ${ }^{35}$. Even though, a high occurrence rate of $T$. gondii infection in cat may be attributed to some important factors including: uncontrolled food and access to contaminated sources, wandering outdoor, humid and temperate climate; and cat abundance. Furthermore, stray cats have been shown to have a higher seroprevalence compared to pet cats, which can be explained by more access to contaminated source and outdoor living ${ }^{31,34,61}$. Additionally, pet cats with an outdoor access are also at an increased risk of infection compared to those kept indoor ${ }^{32,35}$. It has been reported that rural cats show a higher seroprevalence rate of T. gondii compared to urban ones ${ }^{62}$. 
Furthermore, the different diagnostic methods used to detect T. gondii antibodies and oocysts could influence the results. While the different techniques used for anti-T. gondii antibodies detection showed comparably good diagnostic performance, most of the studies aiming to detect $T$. gondii oocysts employed less reliable microscopic methods, which might result in false positives, as oocysts and sporocysts of some other coccidia (e.g. Hammondia hammondi, Besnoitia darlingi) may resemble those of $T$. gondii ${ }^{48}$. It shows the necessity of testing environmental and fecal samples by using specific-PCR aided with amplicon sequencing for identity confirmation ${ }^{63}$.

Felids as key elements in the epidemiology of toxoplasmosis should be considered as a potential threat to animal and public health, due potential oocysts contamination of the environment; such information is still missing in several worldwide locations, so further epidemiological investigations on final hosts would be of special interest for evaluating the status of $T$. gondii infection and risk assessment implementations. Further investigations based on QMRA approaches ${ }^{64,65}$ combining raw data in Felidae with those from the environmental side and those from susceptible hosts will complement the One Health puzzle in defined areas.

In present meta-analysis, it is shown that about one-third of domestic and non-domestic cats have been exposed to T. gondii, and globally about 1 in 50 cats are actively shedding T. gondii or T. gondii-like oocysts. In addition, $16.2 \%$ of the soil samples examined were contaminated with $T$. gondii-like oocysts informing on a broad environmental distribution. Felids are the only final host of T. gondii and play a major role in its life cycle, therefore measures aiming to reduce environmental contamination with $T$. gondii oocysts will be of major interest, and a One Health perspective covering human, animal and environmental health should be taken into account.

\section{Data availability}

The data that supports the findings of this study are available in the supplementary material of this article.

Received: 12 August 2020; Accepted: 13 April 2021

Published online: 04 May 2021

\section{References}

1. Webster, J. P. Review of "toxoplasmosis of animals and humans" by JP Dubey. Parasit. Vectors 3, 112 (2010)

2. Dubey, J. P. The history of Toxoplasma gondii-the first 100 years. J. Eukaryot. Microbiol. 55, 467-475 (2008).

3. Martorelli Di Genova, B., Wilson, S. K., Dubey, J. \& Knoll, L. J. Intestinal delta-6-desaturase activity determines host range for Toxoplasma sexual reproduction. PLoS Biol. 17, 20 (2019).

4. Calero-Bernal, R. \& Gennari, S. Clinical toxoplasmosis in dogs and cats: An update. Front. Vet. Sci. 6, 54 (2019).

5. Lukesova, D. \& Literák, I. Shedding of Toxoplasma gondii oocysts by Felidae in zoos in the Czech Republic. Vet. Parasitol. 74, 1-7 (1998).

6. Dubey, J. Toxoplasmosis-a waterborne zoonosis. Vet. Parasitol. 126, 57-72 (2004).

7. Dubey, J. \& Jones, J. Toxoplasma gondii infection in humans and animals in the United States. Int. J. Parasitol. 38, 1257-1278 (2008).

8. Weiss, L. M. \& Dubey, J. P. Toxoplasmosis: A history of clinical observations. Int. J. Parasitol. 39, 895-901 (2009).

9. Silva, J. C. R., Ogassawara, S., Marvulo, M. F. V., Ferreira-Neto, J. S. \& Dubey, J. Toxoplasma gondii antibodies in exotic wild felids from Brazilian zoos. J. Zoo Wildl. Med. 32, 349-351 (2001).

10. Dubey, J. et al. All about toxoplasmosis in cats: The last decade. Vet. Parasitol. 20, 109145 (2020).

11. Bowie, W. R. et al. Outbreak of toxoplasmosis associated with municipal drinking water. Lancet 350, 173-177 (1997).

12. De Moura, L. et al. Waterborne toxoplasmosis, Brazil, from field to gene. Emerg. Infect. Dis. 12, 326 (2006).

13. Pinto-Ferreira, F. et al. Patterns of transmission and sources of infection in outbreaks of human toxoplasmosis. Emerg. Infect. Dis. 25, 2177 (2019).

14. Isaac-Renton, J. et al. Detection of Toxoplasma gondii oocysts in drinking water. Appl. Environ. Microbiol. 64, 2278-2280 (1998).

15. Aramini, J., Stephen, C. \& Dubey, J. Toxoplasma gondii in Vancouver Island cougars (Felis concolor vancouverensis): Serology and oocyst shedding. J. Parasitol. 20, 438-440 (1998).

16. Mancianti, F. et al. A retrospective molecular study of select intestinal protozoa in healthy pet cats from Italy. J. Feline Med. Surg. 17, 163-167 (2015).

17. Hatam-Nahavandi, K. et al. Microscopic and molecular detection of Cryptosporidium andersoni and Cryptosporidium xiaoi in wastewater samples of Tehran Province, Iran. Iran. J. Parasitol. 11, 499 (2016).

18. Nahavandi, K. H. et al. Molecular typing of Eimeria ahsata and E. crandallis isolated from slaughterhouse wastewater. Jundishapur J. Microbiol. 9, 20 (2016).

19. Shapiro, K. et al. Environmental transmission of Toxoplasma gondii: Oocysts in water, soil and food. Food Waterborne Parasitol. 15, e00049 (2019).

20. Afonso, E., Thulliez, P. \& Gilot-Fromont, E. Transmission of Toxoplasma gondii in an urban population of domestic cats (Felis catus). Int. J. Parasitol. 36, 1373-1382 (2006).

21. DeFeo, M. L., Dubey, J., Mather, T. N. \& Rhodes, R. C. III. Epidemiologic investigation of seroprevalence of antibodies to Toxoplasma gondii in cats and rodents. Am. J. Vet. Res. 63, 1714-1717 (2002).

22. Simon, J. A. et al. A multi-event capture-recapture analysis of Toxoplasma gondii seroconversion dynamics in farm cats. Parasit. Vectors 11, 339 (2018).

23. Veronesi, F. et al. Detection of Toxoplasma gondii in faeces of privately owned cats using two PCR assays targeting the B1 gene and the 529-bp repetitive element. Parasitol. Res. 116, 1063-1069 (2017).

24. Alvarado-Esquivel, C. et al. Seroprevalence of Toxoplasma gondii antibodies in cats from Durango City, Mexico. J. Parasitol. 93, 1214-1216 (2007).

25. Ballash, G. A. et al. Seroprevalence of Toxoplasma gondii in white-tailed deer (Odocoileus virginianus) and free-roaming cats (Felis catus) across a suburban to urban gradient in northeastern Ohio. EcoHealth 12, 359-367 (2015).

26. Ahlers, A. et al. Survey of Toxoplasma gondii exposure in muskrats in a relatively pristine ecosystem. J. Parasitol. 106, 346-349 (2020).

27. Safarpour, H. et al. Global status of Toxoplasma gondii infection and associated risk factors in people living with HIV. Aids (Lond., Engl.) 34, 469-474 (2020).

28. Jafari-Modrek, M., Hasanzadeh, R., Azizi, H. \& Hatam-Nahavandi, K. A Seroprevalence Study of Toxoplasmosis in Female Students in Zahedan, South East of Iran. Iran. J. Public Health 48, 988 (2019).

29. Jones, J. L. et al. Risk factors for Toxoplasma gondii infection in the United States. Clin. Infect. Dis. 49, 878-884 (2009).

30. Aubert, D. \& Villena, I. Detection of Toxoplasma gondii oocysts in water: Proposition of a strategy and evaluation in ChampagneArdenne Region, France. Mem. Inst. Oswaldo Cruz 104, 290-295 (2009). 
31. Kulasena, V., Rajapakse, R., Dubey, J., Dayawansa, P. \& Premawansa, S. Seroprevalence of Toxoplasma gondii in cats from Colombo, Sri Lanka. J. Parasitol. 97, 152-152 (2011).

32. Must, K., Lassen, B. \& Jokelainen, P. Seroprevalence of and risk factors for Toxoplasma gondii infection in cats in Estonia. Vector Borne Zoonot. Dis. 15, 597-601 (2015).

33. Rahimi, M. T. et al. Cats and Toxoplasma gondii: A systematic review and meta-analysis in Iran. Onderstepoort J. Vet. Res. 82, 01-10 (2015).

34. Ding, H., Gao, Y.-M., Deng, Y., Lamberton, P. H. \& Lu, D.-B. A systematic review and meta-analysis of the seroprevalence of Toxoplasma gondii in cats in mainland China. Parasit. Vectors 10, 27 (2017).

35. Must, K., Hytönen, M. K., Orro, T., Lohi, H. \& Jokelainen, P. Toxoplasma gondii seroprevalence varies by cat breed. PLoS ONE 12, 20 (2017).

36. Gomez-Rios, A. et al. Toxoplasma gondii in captive wild felids of Mexico: Its frequency and capability to eliminate oocysts. VectorBorne Zoonot. Dis. 19, 619-624 (2019).

37. Montazeri, M. et al. The global serological prevalence of Toxoplasma gondii in felids during the last five decades (1967-2017): A systematic review and meta-analysis. Parasit. Vectors 13, 1-10 (2020).

38. Moher, D., Liberati, A., Tetzlaff, J. \& Altman, D. G. Preferred reporting items for systematic reviews and meta-analyses: The PRISMA statement. Ann. Intern. Med. 151, 264-269 (2009).

39. Bevins, S. N. et al. Three pathogens in sympatric populations of pumas, bobcats, and domestic cats: Implications for infectious disease transmission. PLoS One 7, 20 (2012).

40. Von Elm, E. et al. The Strengthening the Reporting of Observational Studies in Epidemiology (STROBE) statement: Guidelines for reporting observational studies. Ann. Intern. Med. 147, 573-577 (2007).

41. DerSimonian, R. \& Laird, N. Meta-analysis in clinical trials. Control. Clin. Trials 7, 177-188 (1986).

42. Lee, J., Lee, S., Lee, E. \& Song, K. Nested PCR-based detection of Toxoplasma gondii in German shepherd dogs and stray cats in South Korea. Res. Vet. Sci. 85, 125-127 (2008).

43. Dubey, J. P. \& Beattie, C. P. Toxoplasmosis of Animals and Man 2nd edn. (CRC Press, 2010).

44. Dubey, J. Duration of immunity to shedding of Toxoplasma gondii oocysts by cats. J. Parasitol. 20, 410-415 (1995).

45. Cook, A. et al. Sources of toxoplasma infection in pregnant women: European multicentre case-control study. Commentary: Congenital toxoplasmosis-further thought for food. BMJ 321, 142-147 (2000).

46. Daryani, A. et al. Seroprevalence of Toxoplasma gondii in the Iranian general population: A systematic review and meta-analysis. Acta Trop. 137, 185-194 (2014).

47. Flegr, J., Hrda, S. \& Tachezy, J. The role of psychological factors in questionnaire-based studies on routes of human toxoplasmosis transmission. Cent. Eur. J. Public Health 6, 45-50 (1998).

48. Elmore, S. A. et al. Toxoplasma gondii: Epidemiology, feline clinical aspects, and prevention. Trends Parasitol. 26, 190-196 (2010).

49. Flegr, J. Predictors of Toxoplasma gondii infection in Czech and Slovak populations: The possible role of cat-related injuries and risky sexual behavior in the parasite transmission. Epidemiol. Infect. 145, 1351-1362 (2017).

50. Coutinho, S. G., Lobo, R. \& Dutra, G. Isolation of Toxoplasma from the soil during an outbreak of toxoplasmosis in a rural area in Brazil. J. Parasitol. 20, 866-868 (1982).

51. Jones, J. L. et al. Follow-up of the 1977 Georgia outbreak of toxoplasmosis. Am. J. Trop. Med. Hyg. 94, 1299-1300 (2016).

52. Buffolano, W. et al. Risk factors for recent Toxoplasma infection in pregnant women in Naples. Epidemiol. Infect. 116, 347-351 (1996).

53. Kapperud, G. et al. Risk factors for Toxoplasma gondii infection in pregnancy: Results of a prospective case-control study in Norway. Am. J. Epidemiol. 144, 405-412 (1996).

54. Baril, L., Ancelle, T., Thulliez, P., Goulet, V. \& Tirard, V. Facteurs de risque dacquisition de la toxoplasmose chez les femmes enceintes en 1995 (France). Bull. Épidémiol. Hebdomadaire 20, 73-75 (1996).

55. Arkush, K. D. et al. Molecular and bioassay-based detection of Toxoplasma gondii oocyst uptake by mussels (Mytilus galloprovincialis). Int. J. Parasitol. 33, 1087-1097 (2003).

56. Liu, X.-Y., Wang, Z.-D., El-Ashram, S. \& Liu, Q. Toxoplasma gondii oocyst-driven infection in pigs, chickens and humans in northeastern China. BMC Vet. Res. 15, 1-7 (2019).

57. Gao, X., Wang, H., Wang, H., Qin, H. \& Xiao, J. Land use and soil contamination with Toxoplasma gondii oocysts in urban areas. Sci. Total Environ. 568, 1086-1091 (2016).

58. VanWormer, E., Fritz, H., Shapiro, K., Mazet, J. A. \& Conrad, P. A. Molecules to modeling: Toxoplasma gondii oocysts at the human-animal-environment interface. Comp. Immunol. Microbiol. Infect. Dis. 36, 217-231 (2013).

59. Foroutan, M. et al. The global seroprevalence of Toxoplasma gondii in pigs: A systematic review and meta-analysis. Vet. Parasitol. 269, 42-52 (2019).

60. Dubey, J., Rollor, E., Smith, K., Kwok, O. \& Thulliez, P. Low seroprevalence of Toxoplasma gondii in feral pigs from a remote island lacking cats. J. Parasitol. 83, 839-841 (1997).

61. Taggart, P. L., Caraguel, C. G. \& McAllister, M. M. Fractional seroprevalence rates in common prey species can cause more than half of feral cats to be exposed to Toxoplasma gondii annually. Vet. Parasitol. 288, 109306 (2020).

62. Wang, Z. T., Verma, S. K., Dubey, J. P. \& Sibley, L. D. The aromatic amino acid hydroxylase genes AAH1 and AAH2 in Toxoplasma gondii contribute to transmission in the cat. PLoS Pathog. 13, e1006272 (2017).

63. Robertson, L. J. et al. Are molecular tools clarifying or confusing our understanding of the public health threat from zoonotic enteric protozoa in wildlife?. Int. J. Parasitol. Parasit. Wildl. 9, 323-341 (2019).

64. Opsteegh, M., Prickaerts, S., Frankena, K. \& Evers, E. G. A quantitative microbial risk assessment for meatborne Toxoplasma gondii infection in The Netherlands. Int. J. Food Microbiol. 150, 103-114 (2011).

65. Deng, H. et al. Digging into Toxoplasma gondii infections via soil: A quantitative microbial risk assessment approach. Sci. Total Environ. 20, $143232(2020)$

\section{Acknowledgements}

We are especially appreciative of Dr. Jitender P. Dubey and Dr. Solange M. Gennari for their kind help and constructive comments.

\section{Author contributions}

Conceptualization, K.H.N., R.C.B., and E.A.; methodology, A.S.P., K.H.N., M.Z., A.D., and M.T.R.; formal analysis, E.A., and M.T.R.,; investigation, R.C.B., A.S.P., and K.H.N.; data curation, E.A., and A.D.; writing-original draft preparation, A.S.P., M.T.R., K.H.N.; and A.D.; writing-review and editing, E.A., R.C.B., and M.Z. All authors have read and agreed to the published version of the manuscript. 


\section{Funding}

The article was funded by Research Center for Infectious Diseases and Tropical Medicine, Tabriz University of Medical (Grant No. 63205). Rafael Calero-Bernal is part of the TOXOSOURCES consortium supported by the funding from the European Union's Horizon 2020 Research and Innovation Programme under the grant agreement No 773830: One Health European Joint Programme.

\section{Competing interests}

The authors declare no competing interests.

\section{Additional information}

Supplementary Information The online version contains supplementary material available at https://doi.org/ 10.1038/s41598-021-89031-8.

Correspondence and requests for materials should be addressed to E.A.

Reprints and permissions information is available at www.nature.com/reprints.

Publisher's note Springer Nature remains neutral with regard to jurisdictional claims in published maps and institutional affiliations.

(c) (i) Open Access This article is licensed under a Creative Commons Attribution 4.0 International License, which permits use, sharing, adaptation, distribution and reproduction in any medium or format, as long as you give appropriate credit to the original author(s) and the source, provide a link to the Creative Commons licence, and indicate if changes were made. The images or other third party material in this article are included in the article's Creative Commons licence, unless indicated otherwise in a credit line to the material. If material is not included in the article's Creative Commons licence and your intended use is not permitted by statutory regulation or exceeds the permitted use, you will need to obtain permission directly from the copyright holder. To view a copy of this licence, visit http://creativecommons.org/licenses/by/4.0/.

(C) The Author(s) 2021 